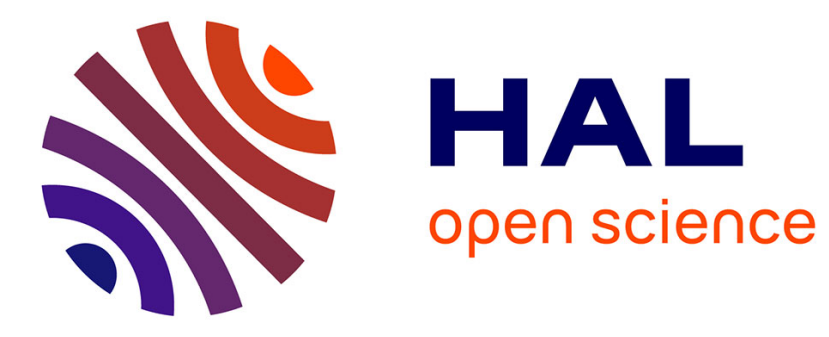

\title{
Using Logic Concepts on Six Sigma
}

Caique Z. Kirilo, Jair M. Abe, Luiz Lozano, Renato H. Parreira, Eduardo P. Dacorso

\section{To cite this version:}

Caique Z. Kirilo, Jair M. Abe, Luiz Lozano, Renato H. Parreira, Eduardo P. Dacorso. Using Logic Concepts on Six Sigma. IFIP International Conference on Advances in Production Management Systems (APMS), Sep 2016, Iguassu Falls, Brazil. pp.36-42, 10.1007/978-3-319-51133-7_5 . hal01615787

\section{HAL Id: hal-01615787 \\ https://hal.inria.fr/hal-01615787}

Submitted on 12 Oct 2017

HAL is a multi-disciplinary open access archive for the deposit and dissemination of scientific research documents, whether they are published or not. The documents may come from teaching and research institutions in France or abroad, or from public or private research centers.
L'archive ouverte pluridisciplinaire HAL, est destinée au dépôt et à la diffusion de documents scientifiques de niveau recherche, publiés ou non, émanant des établissements d'enseignement et de recherche français ou étrangers, des laboratoires publics ou privés.

\section{(c)(1)}

Distributed under a Creative Commons Attribution| 4.0 International License 


\title{
Using Logic Concepts on Six Sigma
}

\author{
Caique Z. Kirilo, Jair M. Abe, Luiz Lozano, Renato H. Parreira, and Eduardo \\ P. Dacorso \\ Paulista University, São Paulo, Brazil \\ \{zaneti, luiz, renato\}@paradecision.com
}

\begin{abstract}
Decision Making process is key to success. With this in mind, this paper discusses the implementation of Paraconsistent Logic to the Six Sigma concepts. It is known that the human factor can be risky, so it can benefit with the addition of some artificial intelligence such as Paraconsistent Logic. Applying the Paraconsistent Decision-Making Method can minimize the human factor risk, avoiding rework, as it eliminates any discrepancy among the opinions of the specialist involved on the decision making process.
\end{abstract}

Keywords: Decision-making · Six sigma · Quality · Paraconsistent Annotated Evidential Logic E $\tau$

\section{Introduction}

This paper proposes an improvement on the Six Sigma concept by reducing the human factor risk causes by the misallocation of human resources for the execution of tasks or the misapplication of the DMAIC method. The proposed is a method based on an expert system Paraconsistent Annotated Evidential Logic E $\tau$. Such system identifies inconsistencies in the decisions taken by experts in the program, making possible to deal with these inconsistencies and, also to identify if the experts have the necessary knowledge to take the right decision. Six Sigma is a process based entirely on the human factor, so applying an artificial intelligence will minimize errors caused by it making Lean Six Sigma stronger and more efficient, empowering the process of quality improvement.

We can best exemplify the idea as follows: imagine many managers and employees participating in a brainstorm where the goal is to create a cause and effect diagram for a particular problem, in that meeting will be people from different hierarchies and influence, then if we want to get the most reliable results in this brainstorm we need to shield the environment so that factors such as appearance, influence or intimidation will not interfere in the decision-making process.

Integrating paraconsistent logic in the creation of this cause and effect diagram through software is a solution to make the environment that is happening brainstorm get as close as possible to neutrality. In that way participants will register their opinions transparently and totally focused on the problem, thus obtaining more accurate results. 


\section{Six Sigma - Backgrounds}

Based on studies of Werkema [1], Lean Six Sigma is a quantitative management strategy starting from the number of faults in the production or product process. It aims to improve them to increase customer satisfaction and generate a higher profit margin. It must be implemented "top-down" and all employees, regardless of their segment or hierarchy, should be part and have knowledge about the program. Each of them will have responsibilities and tasks in order to have a good Lean Six Sigma implementation. Each employee assumes a position and respective responsibilities described below:

- Sponsor of Lean Six Sigma: The person with the highest executive level in the company, responsible for defining all the factors necessary for the implementation of the program.

- Sponsor Facilitator: It is one of the company directors. It has the function of advising the Lean Six Sigma Sponsor in implementing the program.

- Champions: are directors or managers of the company who is responsible for supporting the projects and remove difficulties for its development.

- Master Black Belts: They are professionals who advise the Sponsors and Champions, which must have great ability to teach and act as mentors for Black Belts and Green Belts.

- Black Belts: They are team leaders, whose function is to coordinate projects. Must have a high technical knowledge and a number of qualities that characterize as being able to perform this function.

- Green Belts: They are members of teams led by Black Belts or leading teams in conducting functional designs.

- Yellow Belts: They are usually supervisors, properly educated and trained to understand the basics of the program. It has the function of supervising the program is well implemented across the organization and run projects focused on development.

- White Belts: They are professionals operating company level, properly educated and trained in the program. They have the function to support the Green Belts and Black Belts.

This hierarchy is respected when Paraconsistet Logic is applied to these concepts.

\section{The DMAIC Method in Six Sigma}

One of the Lean Six Sigma infrastructure elements is the establishment of teams to execute projects that strongly contribute to the achievement of strategic goals of the company. The development of these projects is carried out based on a method called DMAIC [2]. The DMAIC method consists of 5 steps, Define, Measure, Analyze, Improve and Control.

- D - Define: Define the precise scope of the project. 
- M - Measure: Determine the location or focus of the problem.

- A - Analyze: To determine the causes of each priority problem.

- I - Improve: To develop, evaluate and implement solutions for each priority problem.

- $\mathbf{C}$ - Control: To ensure that the scope of the long-term goal is maintained.

\section{Human Errors in Six Sigma}

No doubt this is the most sensitive part of Six Sigma, the people who are responsible to make it work are the same that causes its fail. Weighing it [3] addressed this issue based on the studies of Schmidt [4] and the result was a list of most significant factors involving human error. The Paraconsistent Logic has the intention to minimize or eliminate the negative impacts caused by these factors.

Misinterpretation: To ensure uniform interpretation of the words is necessary to provide precise definitions, plus auxiliary tools such as checklists and examples. They should also be given detailed information and examples of how to calculate, summarize, record, etc. On critical issues, should provide formal training, along with tests to check the "capacity" of candidates for sensors on the process [3].

Inadvertent error: Inadvertent error is unintentional, unpredictable and often unconscious, that is, the person who makes the mistake is not, then, conscious of having committed it. The data produced by an inadvertent error has a random characteristic, which is useful for identifying errors of this type. The choice of solution for this type of error is somewhat limited because the root cause of inadvertent mistakes is an inherent weakness in the human been, so to say, the inability to keep an eye indefinitely [3].

Lack of technique: The error for lack of technique is the result of incomplete knowledge by the human sensor. Some people have developed a more skillful way - some kind of "trick", i.e. a small difference in the method that represents a big difference in the results. Those who know the "trick" get superior results; others, not. The solution in this case is to study the methods used both by those who have superior performance, as for those that have underperformed. These studies have identified the "tricks" that can then be transferred to all employees through training or embedded technology [3].

Conscious error: The conscious mistake is intentional. The person who made it is aware of that, and intends to continue, often as a form of defense against real or imagined injustices [3].

Dissimulation: Dissimulation is a deliberate alteration of data collected for a variety of usually selfish purposes: reducing workload, escape from unpleasant tasks, self-promotion, fear of being punished for delivering bad news. The reduction of dissimulation can be achieved in part by the establishment of an environment that adopts open communication, which requires leadership by example, senior management [3].

Distortion: Distortion and dissimulation are similar, but there are subtle differences. In dissimulation the human sensor knows the facts and alters consciously. The distortion is not necessarily consciously, the possible existence of 
interior forces influencing the human sensor response (e.g., fixed ideas due to the habit). The distortion can even be results from the human sensations and feelings. An example is the test conducted by a razor blade manufacturer, in which the reports of the employees who did the test were distorted because they knew the number of beards already made with the blade being tested [3].

Uselessness: The feeling of worthlessness is another source of conscious error. If the employees find out that their reports do not lead to anything, they stop making them. The situation is even worse if workers find that their reward for acting as sensors is an unjustified guilt [3].

\section{An Expert System Based on Paraconsistent Logic}

Studies based on [5], a synthesized form of PDM, a support method in the decision-making process based on Paraconsistent Logic, which uses the experts' experience to check the feasibility or unfeasibility of a given situation.

From an initial issue called proposition, factors that impact the feasibility or unfeasibility of the matter must be determined. These factors can be divided into sections that are analyzed in order to extract the most of the experience from the specialists.

To make a feasibility analysis of an enterprise for decision making, planning is under the coordination of a particular person (the entrepreneur himself, an engineer, a consultant etc.). This person works the data in a way to translate them for the language of $\mathrm{E} \tau$ logic. This will be called expert knowledge engineer (CE) [5].

According to [6] the Paracon-sistent Decision-Making Method has 8 steps:

1. To set the level of demand of the decision whether to take.

2. Select the most important factors and most influential in the decision.

3. Establish the sections for each of the factors, if necessary. The quantity of sections can be chosen depending on the desired granularity/precision.

4. Build the database, which consists of the weights assigned to the factors (When necessary to distinguish them by importance) and the values of favorable evidence (or degree of belief) (a) and contrary evidence (or degree of disbelief) (b) assigned to each factor-sections combination. The weights and the evidence values are assigned by experts chosen conveniently. The database may also be built with stored statistical data obtained from previous experience in performing similar undertakings.

5. Do field research (or data collection) to check, in this case, where section (condition) each factor is.

6. Get the value of the favorable evidence $\left(a_{i, R}\right)$ and the value of the evidence against $\left(b_{i, R}\right)$ resulting, with $1 \leq \mathrm{i} \leq \mathrm{n}$, for each of the factors $\left(F_{i}\right)$ chosen. The sections found in the search $\left(S_{p j}\right)$ by application of the techniques of maximization (operator MAX) and minimizing (MIN operator) of $\mathrm{E} \tau$ logic.

7. Get the degree of favorable evidence $\left(a_{w}\right)$ and the unfavorable evidence $\left(b_{w}\right)$ of global analysis of the points representing the factors chosen in the lattice $\tau$

8. Making the decision, applying the decision rule or algorithm para-analyzer. 


\section{$6 \quad$ Unifying Concepts}

Unifying the concepts of Paraconsistent Logic with Six Sigma is relatively simple; it is possible to draw an equivalence between these two issues.

Paraconsistent Logic has a role of knowledge engineer, who will be responsible for assigning and coordinating the specialists' tasks. The Lean Six Sigma Sponsor will play that role. As he/she is the person who has the macro view of the company, however has access to and power over the micro views.

Other specialists will perform different tasks as described in Chapter 2 of this paper, these experts according to Paraconsistent Logic can have certain weight in decision-making, this weight is set according to the degree of experience that the expert has with the issue at hand. For example, a Green Belt can opine better on a particular issue than the Black Belt due to have more operational knowledge, as the Black Belt has more management experience.

The experts opine on predetermined tasks, stipulated by the Lean Six Sigma Sponsor. He/She will play the role of the knowledge engineer and will split the task on several factors, which will be investigated by all experts. Thus experience of all members will be utilized optimally. The contradictions will be canceled by PDM, making the whole process more effective. Following is illustrated the union of concepts.

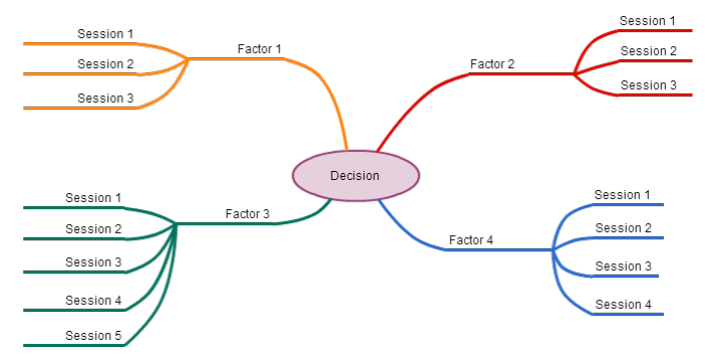

Fig. 1. The MPD concept

The decision is made upon certain factors, shown in Figure 1. The factors are split into sections to better specify function the issue being dealt. That is, the issue to be addressed is thoroughly analyzed before being discussed, and when discussed will be extensively analyzed.

Figure 2 shows a fictitious example of how you deploy a part of the six sigma in paraconsistent logic. The program members will respond to certain factors with a percentage of certainty and uncertainty, and then the logic will do the calculations that will eliminate the contradictions.

This way the human error causes can be eliminated as the tasks will be extensively treated during its course, so, before been executed. It is also possible to ensure that all program members effectively understand the importance of a particular task. 


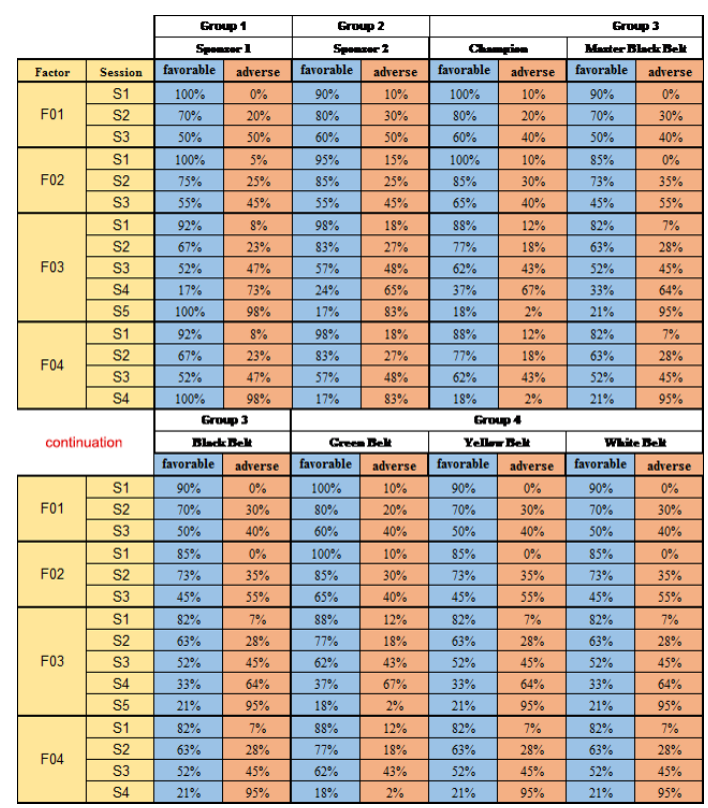

Fig. 2. The Union of Concepts

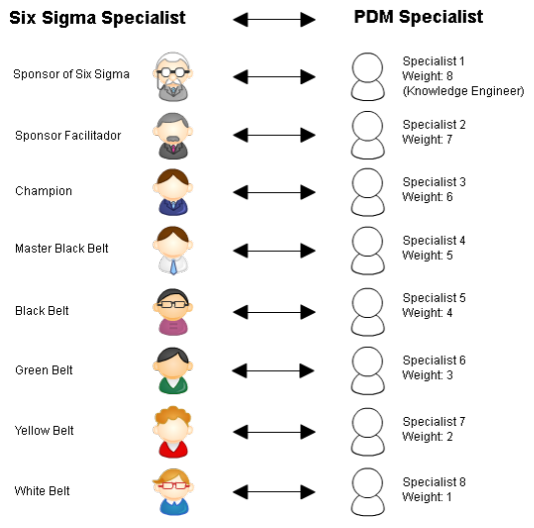

Fig. 3. The Specialist Association

This system can be implemented at any time the progress of the Six Sigma program. There is a Decision Making Software developed by ParaDecision Company that simplifies the implementation of the PDM. There is a free version on the website www.paradecision.com.

Figure 3 shows how it can be made the integration between the experts of Six Sigma and paraconsistent logic. The weights assigned to the experts will impact 
the decision-making, then in certain situations these weights can be changed according to the greater knowledge of the expert in question.

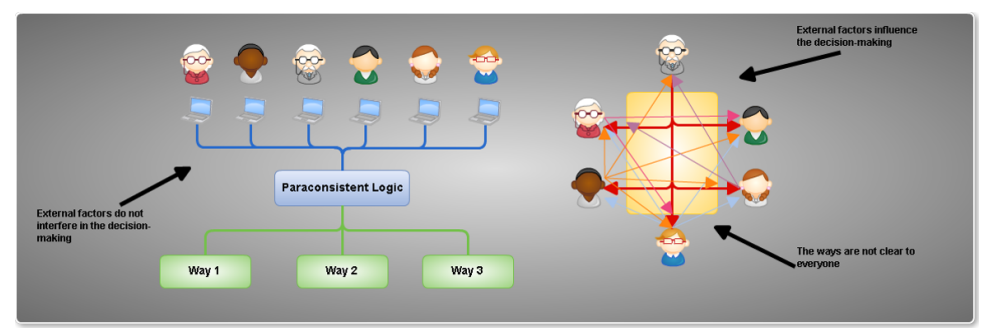

Fig. 4. Difference between two ways of making decisions

\section{Conclusions}

This paper, though bring a more superficial view of the subject, invites the reader to reflect on the use of paraconsistent logic as a way to improve the implementation of Six Sigma and mitigate their vulnerabilities.

It is possible with the use of an artificial intelligence minimize human errors that put at risk the program. The intention was never eliminated the human's deci-sion-making process; on the contrary, the intention is to improve the experience of the human being and makes it less susceptible to failures throughout the process.

\section{References}

1. Werkema, C.: Criando a Cultura Seis Sigma. Werkema Editora (2004)

2. Werkema, C.: Métodos PDCA e DMAIC e suas Ferramentas Analíticas, vol. 1. Elsevier Brasil (2013)

3. Werkema, C.: Perguntas e Respostas sobre o Lean Seis Sigma. 2 Ed. Rio de Janeiro. Elsevier Brasil (2011)

4. Schmidt, P., dos Santos, J.L., Arima, H.: Fundamentos de Auditoria de Sistemas. Atlas (2006)

5. Carvalho, Fábio Romeu de: Aplicação de Lógica Paraconsistente Anotada em Tomadas de Decisão na Engenharia de Produção. Ph.D. thesis, Universidade de São Paulo (2006)

6. Abe, J.M., Akama, S., Nakamatsu, K.: Introduction to Annotated Logics: Foundations for Paracomplete and Paraconsistent Reasoning, vol. 88. Springer-Verlag (2015) 